\title{
Symmetric Metrics for Materials
}

Congress, the pressure transducer of public opinion, is squeezing our formerly sacrosanct budgets, not just with dollar dings but with relevance requirements. Written on all walls (with expletives deleted) is "Scientists beware! Justify your existence or perish." In response, we panic in our typically quantitative, logical, and methodical manner. We wring our hands as we strain our brains to devise justifications for basic research. Neither worry nor wisdom has helped us much so far.

You'd think we materials researchers would find justification easier than would, say, the high energy physicists (but not nearly as easy as the viscerally self-justifying biomedical community). Still, we are pummeled by demands to explain ourselves better and, of all things, in plain English.

A recent well-meant jibe from a medical doctor pointed out that "scientists at the leading edge are in the business of change but get nervous at the prospect of change in science policy."1 This was an MD telling us that we are behaving like everyone else with a special interest under siege, whereas we should be welcoming what we are already familiar with. One wonders if vaccine experts welcome the corresponding virus.

Let's take a fresh look, not just at our interrogators' explicit questions, but also at the character of the answers that really work for them. They ask us about new products, new jobs, quality of life, trade deficits, and so forth. Their rhetoric is couched in such altruistic metrics. We hear the questions as if posed at a dissertation defense rather than in a congressional hearing and persist in trying to explain the nation's return on its research investment, the eventual value of new knowledge, the intricacies of technological gestation, incubation and innovation (and whether it's all linear or not), and the foolhardiness of mortgaging our technological future.

The MRS Bulletin values your opinion.
Write to:
Editor, MRS Bulletin
Materials Research Society
9800 McKnight Road
Pittsburgh, PA $15237-6006$
Fax (412) 367-4373

As experts not only in change but also in measurement, we try futilely to quantify the impact of basic research. Inevitable frustration results because we have blindly adopted the metrics handed us. Look instead at the metrics our legislators themselves rely on in their own pursuits-at how they measure their own success.

Strap yourself in for the revelation! They campaign and survive on the basis of polls, media coverage, and personal charisma. We must devise for research metrics symmetric to these to impress leaders whose expertise in "a chicken in every pot" sloganeering has no respectable match in research circles. Remember, when friendly legislators tried our usual factual approach to rescue the SSC, they merely accelerated its demise. You see, it's not the people or the message but the tactics that prevail. To prove this contention, we need only cite recent adulation from Vice President Al Gore, a leading advocate of science and technology. He explained that superconductivity had been a dormant field and then, lo and behold, high $\mathrm{T}_{\mathrm{c}}$ was discovered and it "went from a basic research backwater to the cover of Newsweek." 2 Not MRS Bulletin and Physics Today, or even Scientific American, but Newsweek!

Although castigated by conservative colleagues, those who opt first for press conferences and releases to the New York Times have foreseen the solution to our dilemma. It is no longer adequate to be featured in a PBS Nova special or on CNN's Science and Technology Report. Their audiences only duplicate the readership of Scientific American-a relatively tiny number of thoughtful enthusiasts. Refereed publications, citations, invited talks, copyrights, and patents are now passé metrics. Even a Nobel Prize is worth only as much as the invitations it generates to hearings and cocktail parties in the capital.

We need sound bites on the six and eleven o'clock TV news. We need notoriety in whatever form available:

- Music videos on materials,

- Sensational materials law suits,

- Tabloid photos of materials research in compromising positions,

- Visits by the rich and famous to our MRLs,

- Real and imagined materials disasters such as oil spills, nuclear winter, and earthquake-induced building and bridge collapses,
- International incidents, and

- Grand jury indictments (but, please, no convictions).

We are locked in a political, not pedagogical, battle for survival. As our doctor colleague also preached," "First do no harm." No harm will be done, of course, by demonstrating links of basic research to national needs, but this is certainly not a sufficient condition for support, and may not even be a necessary one. Have no doubt that our victories will rest on the sensational. Who believes, for example, that the Hubble survived its trouble just because we fixed it? To discount the public's fascination with Roddenberry's and Sagan's portraits of "Billions upon Billions of stars in the universe" is not only to bury one's head in the sand, but to be condemned to inhale it.

We must grudgingly agree with Koshland, who advises that if government wants to solve difficult problems, it can do so with a "policy that uses scientific, not emotional, standards. ${ }^{3}$ But before anyone is authorized (much less appropriated) to solve a problem, the political will must be there. A recent letter to Physics Today offers a prescription for training physicists (the least trainable among us) to score high against a politically real metric. ${ }^{4}$ The letter argues that we must not just communicate knowledge but we must impress audiences with pictures, color graphics, simple moving language for the nontechnical, and all the other techniques of drama and psychology inherent in advertising Our science curricula should require courses in these skills so future generations can market science effectively.

Once we get the hang of the "medium is the message" tactic, we can measure our success by how many candidates promising "photovoltaics on every roof and cellular phones on every wrist" actually get elected.

\section{E.N. KAUFMANN}

1. Virginia Weldon, MD (Monsanto), at the "Forum on Science in the National Interest: World Leadership in Basic Science, Mathematics, and Engineering" (National Academy of Sciences, January 31, 1994, Washington, DC).

2. Albert Gore, op. cit. (February 1, 1994).

3. Daniel E. Koshland, Science 263

(February 25, 1994) p. 1071.

4. James B. Cole, Physics Today 47 (2)

(February 1994) p. 125-126. 